\title{
Randomized clinical trial of the effect of a fixed or increasing milk allowance in the first 2 weeks of life on health and performance of dairy calves
}

\author{
W. A. Knauer, ${ }^{* 1}$ S. M. Godden, ${ }^{*}$ S. M. McGuirk, $†$ and J. Sorg* \\ *Department of Veterinary Population Medicine, University of Minnesota, St. Paul 55108 \\ †Professor Emeritus, Department of Medical Sciences, University of Wisconsin-Madison, Madison 53706
}

\begin{abstract}
The objective of this study was to describe the effect of offering a fixed or increasing milk allowance in the first 1 to 2 wk of life. We hypothesized that calves offered a fixed amount of milk early in life would not experience more scours, but rather would experience improved health and growth compared with calves that had their daily milk allowance slowly increased over a period of 1 to $2 \mathrm{wk}$. This randomized controlled clinical trial was conducted on 5 dairy farms in Minnesota with both a summer (June-August 2016) and winter (December-February 2017) period of enrollment. Heifer calves were enrolled at birth, weighed, and systematically assigned by birth order to either the slowly increasing (INC) control group or fixed allowance (FIX) treatment group by farm personnel. Calves assigned to the INC group were slowly increased from 4 to $5 \mathrm{~L} / \mathrm{d}$ to gradually reach the full peak milk allowance of 6 to 8 L/d over a 7- to 14-d period, whereas calves assigned to the FIX group were offered a full peak milk allowance of 6 to $8 \mathrm{~L} / \mathrm{d}$ beginning on $\mathrm{d} 1$ after birth. The average FIX calf consumed an extra $14 \mathrm{~L}$ of milk as compared with INC calves over the first 2 wk of life, corresponding to an average INC intake of $5 \mathrm{~L} / \mathrm{d}$ during first 1 to 2 wk of life as compared with an average intake of $6.8 \mathrm{~L} / \mathrm{d}$ in FIX calves. Study technicians visited all farms weekly to collect health and performance data. Multivariable mixed models were used to describe the effect of treatment (INC/FIX) on 3-wk average daily gain $(\mathrm{kg} / \mathrm{d}), 3$-wk weight $(\mathrm{kg})$, and hip height at wk 1,3 , and 7 , controlling for the effect of season, birth weight, and the random effect of calf within farm. Multivariable logistic regression models were used to describe the effect of treatment on odds of technician
\end{abstract}

Received December 18, 2017.

Accepted May 5, 2018.

${ }^{1}$ Corresponding author: knaue020@umn.edu and producer reported health events. A total of 1,264 heifer calves were enrolled (FIX $\mathrm{n}=641$; INC $\mathrm{n}=$ 623) with no difference in enrollment weight or hip height between groups. By 3 wk of age, FIX calves weighed $1.4(0.59) \mathrm{kg}$ more than INC calves, though the magnitude of this difference varied depending on the period of time INC calves were slowly increased in milk allowance ( 7 vs. 10 vs. 14 d). Calves in the FIX group grew $0.1 \mathrm{~kg} / \mathrm{d}$ faster and were taller at wk $3(0.3$ $\pm 0.15 \mathrm{~cm})$ of life. Forty-two percent $(536 / 1,264)$ of all enrolled calves had a first treatment event, with no effect of treatment on technician-reported health scores and no overall effect on producer-reported treatment or mortality events. Under the conditions of this study, offering a fixed milk allowance from d 1 of life improved calf growth during the first $3 \mathrm{wk}$ as compared with a gradual increase in milk allowance, with no detrimental effect on calf health.

Key words: calf health, calf performance, milk feeding

\section{INTRODUCTION}

The health and growth of preweaning dairy calves is an important concern for dairy producers, affecting animal welfare and future performance as well as the short- and long-term economic viability of the dairy enterprise (DeNise et al., 1989; Faber et al., 2005; Soberon et al., 2012). Therefore, dairy producers must adopt management practices that produce a well-grown healthy calf. The level of nutrient intake from milk during the preweaning period is one management factor associated with preweaning health, growth, and, in most studies, improved milk production in the adult cow. Increasing milk intake above conventional rates (e.g., $10 \%$ of birth weight or approximately $4 \mathrm{~L} / \mathrm{d}$ ) to enhanced, accelerated, full potential, or ad libitum volumes (e.g., $20 \%$ of birth weight or approximately $\geq 8$ $\mathrm{L} / \mathrm{d}$ ) has been associated with an enhanced immune response (Foote et al., 2005; Quigley et al., 2006; Ballou et al., 2015), increased resistance to diarrheal pathogens (Ollivett et al., 2012), improved growth rate, and improved first-lactation milk production (Foldager and 
Krohn, 1994; Bar-Peled et al., 1997; Soberon and Van Amburgh, 2013). As producers are learning about these benefits, the dairy industry is seeing a steady increase in adoption of the practice of feeding increased levels of milk during the preweaning period (USDA, 2016).

Unfortunately, one specific period that remains neglected within the preweaning nutrition program is the first 1 to 2 wk after birth. Producers have long been concerned that bringing calves onto high volumes of milk too quickly will result in nutritional scours or other digestive problems. As a result, most producers continue to use a traditional program of slowly increasing the volume of milk fed over a period of 1 to $2 \mathrm{wk}$ or longer before reaching the target peak daily milk allowance. For example, in a recent survey of 38 upper Midwest dairies using automatic feeding systems, the average calf started at an average allowance of $5.4 \mathrm{~L} / \mathrm{d}$ and increased to a peak feeding level of approximately $8 \mathrm{~L} / \mathrm{d}$ over a period of $3 \mathrm{wk}$ (Jorgensen et al., 2017). Given what we already know about the advantages of increased milk feeding during the entire preweaning period, it is very possible that this slowly increasing period for milk may be restricting nutrient intake in the days after birth, resulting in impaired immune function, health ,and growth during the first 2 wk of life, when calves are at greatest risk of morbidity. Observational studies have reported that, when allowed ad libitum access in the first days of life, calves will drink up to $12 \mathrm{~L} / \mathrm{d}$ without causing scours, with the average calf drinking $8 \mathrm{~L} / \mathrm{d}$ by $4 \mathrm{~d}$ of age (Jasper and Weary, 2002; de Passillé et al., 2014). Furthermore, a recent observational study offered ad libitum milk during the first $5 \mathrm{~d}$ of life and reported that calves that remained healthy up to $28 \mathrm{~d}$ of age were more likely to have consumed more milk during the first $5 \mathrm{~d}$ compared with calves that experienced a morbidity event (de Passillé et al., 2014). We believe that there may be several advantages to allowing calves the option of consuming more milk from d 1 of life; however, this hypothesis requires formal investigation.

The objective of our study was to complete a randomized controlled field study to describe the effect of offering a fixed amount of milk immediately from d 1 (versus a traditional slow increase program) on calf health and growth in the preweaning period. We hypothesized that calves allowed the option to drink more milk starting from d 1 would not be at greater risk for scours, would experience improved weight gain, and would experience improved health during the preweaning period compared with calves that are more gradually increased in their milk allowance over a 7 - to 14-d period before eventually reaching the target peak daily milk allowance.

\section{MATERIALS AND METHODS}

This study was approved by the University of Minnesota Institutional Animal Care and Use Committee (Protocol \# 1601-33432A).

\section{Herd Selection}

This randomized controlled clinical trial was conducted on a convenience sample of 5 large commercial dairy farms in Minnesota, representing predominately the Holstein breed, with calf enrollment occurring from June to August 2016 (SUM) and again from December to February 2017 (WIN). Participating herds must have housed calves individually or as pairs (i.e., no group housing) during the preweaning period and fed either pasteurized whole milk or milk replacer at a minimum full feeding program of $6 \mathrm{~L}$ per calf per day. Additionally, herds must have been using a milk-feeding program that slowly increased the daily milk allotted from a minimum of 4 to $5 \mathrm{~L} / \mathrm{d}$ to the full feeding rate over a period of 7 or more days. Participating herds agreed to keep detailed calf health records, to adhere to the study protocols, and to allow study technicians to visit the farm on a weekly basis for study related activities. Participation was voluntary.

\section{Calf Enrollment and Management}

Newborn Holstein heifer calves were enrolled by herd staff at birth and assigned to 1 of 2 treatment groups using a systematic randomization process based on birth order. Increasing (INC) calves were offered a gradually increasing amount of milk over the first 7 or more days of life as per the farm's current feeding program (e.g., $4 \mathrm{~L} / \mathrm{d}$ for $7 \mathrm{~d}$, $6 \mathrm{~L} / \mathrm{d}$ from $7-14 \mathrm{~d}$, and $8 \mathrm{~L} / \mathrm{d}$ for the remainder of the feeding period). Fixed level (FIX) calves were immediately offered the peak or maximum level of milk the farm provides after the first feeding of colostrum. The study investigators (W. A. Knauer) initially trained herd staff on enrollment and feeding procedures, health screening, and record keeping and regularly visited farms with student technicians to monitor compliance. After INC calves were increased to their full milk allotment, both treated and control groups were offered the same amount of milk for the remainder of the preweaning period. Calves exited the study when they were weaned from milk (approximately $7-8 \mathrm{wk}$ ).

\section{Data Collection}

An initial questionnaire was completed by each participating herd to describe general herd character- 
istics (e.g., herd size), calf facilities (e.g., housing, bedding), and calf-management programs (e.g., newborn care, colostrum, milk feeding plan, starter and water management, treatment protocols, vaccinations, and weaning procedures). For each calf enrolled, the calf identification, treatment group, and birth weight (using an electronic scale; LVS-700, LW Measurements LLC, Rohnert Park, CA) were recorded by herd staff. All calf illness or death events were diagnosed, treated, and recorded by farm personnel. Farm personnel working with calves were blinded to study objectives and hypotheses but, out of necessity to accommodate feeding, could not be blinded to the treatment group allocation.

A team of veterinary student technicians visited each farm each week to collect enrollment information including producer-recorded records of treatment or mortality events and biological samples and measurements. A minimum of $1 \mathrm{~mL}$ of venous blood was collected via jugular venipuncture from each enrolled calf at 1 to $7 \mathrm{~d}$ old and serum total protein (STP; $\mathrm{g} / \mathrm{dL}$ ) was measured using a digital refractometer (MISCO Palm Abbe Model PA203X, MISCO, Cleveland, OH). For the first $3 \mathrm{wk}$ of life, study technicians also completed a health score for each calf using the University of Wisconsin, School of Veterinary Medicine Calf Health App (iTunes, Apple Inc., Cupertino, CA). Study technicians weighed each enrolled calf at $3 \mathrm{wk}$ using an electronic scale (LVS-700, LW Measurements LLC). At wk 1, 3, and 7 of life hip heights $(\mathrm{cm})$ of enrolled calves were measured using a hippometer (Nasco, Fort Atkinson, WI). Student technicians were also blinded to study objectives and hypotheses.

\section{Statistical Analysis}

Sample Size. An a priori sample size calculation estimated that a minimum of 700 calves per treatment group will provide in excess of $95 \%$ confidence and $80 \%$ power to detect a $20 \%$ reduction in morbidity in the treated compared with the control group. This assumes a baseline (control group) morbidity of 35\% (USDA, 2010) and a biologically and economically important reduction to $28 \%$ morbidity in the treated group.

Descriptive Analysis. Descriptive statistics were generated to describe farm characteristics including milk feeding plans, peak milk allotment, extra milk consumed by the FIX group, and to describe overall, by treatment group and by season, calf health and performance characteristics. This included STP (g/ $\mathrm{dL})$, birth weight $(\mathrm{kg})$, calf weight at wk $3(\mathrm{~kg})$, growth rates (ADG; $\mathrm{kg} / \mathrm{d}$ ) between birth and wk 3, weekly technician-recorded health scores for the first $3 \mathrm{wk}$, and producer-recorded treatment rates (overall and by specific disease) and mortality rates between birth and weaning. Technician-recorded health scores were dichotomized to describe abnormal health scores, as described by McGuirk (2008); diarrhea was (DIA) a fecal score $\geq 2$, respiratory illness (RESP) was a respiratory score $\geq 4$, and sickness (SICK) DIA + RESP. Correlation among continuous variables was assessed and all continuous variables were plotted to check for normality. We tested the effect of treatment and season on continuous and categorical outcomes of interest by $t$-test and chi-squared analysis, respectively.

Calf Growth. Multivariable linear mixed models (v 9.4. SAS, SAS Institute, Cary, NC) were used to describe the effect of treatment on calf health and growth outcomes. As a first step, univariable models were used to explore the relationship between the main explanatory variable of interest (FIX/INC) and continuous outcomes, including ADG to $3 \mathrm{wk}(\mathrm{kg} / \mathrm{d})$, wk-3 weight $(\mathrm{kg})$, and hip height at 3 and $7 \mathrm{wk}(\mathrm{cm})$. The association between these outcomes and other significant potential confounders or explanatory variables were also assessed, including STP, birth weight, breed, and season (WIN/SUM). Predictors significant at $P<0.2$ were offered to the full model and were removed in a backward step-wise fashion until all predictors were significant at $P<0.05$. Treatment group (FIX/INC) was forced into these models, regardless of significance. Next, biologically plausible 2 -way interactions were explored and models were stratified if significant interactions were found. Farm was initially tested as a fixed effect, but was ultimately controlled for as a random effect, with calf nested within farm. As a secondary analysis, to explore the effect of duration from birth to reaching peak milk allowance (days), farms were classified into 3 categories describing time to peak in the INC group (peak $1=7 \mathrm{~d}$ to peak milk; peak $2=10 \mathrm{~d}$ to peak milk; and peak $3=14 \mathrm{~d}$ to peak milk). An interaction term that tested time to peak $\times$ treatment group was tested for all continuous outcomes. If a significant interaction was found, models were then stratified by time to peak.

Calf Health. Multivariable logistic regression was used to investigate the effect of treatment on health outcomes, including the odds of a producer-reported morbidity event [e.g., first, second, third treatments and clinical diagnosis of scours (yes/no)] and technicianderived health scores indicative of illness (DIA, RESP, SICK). The main predictor in each model was treatment (FIX/INC), and all models offered to control for the effect of season (WIN/SUM), breed, failure of passive transfer (yes/no), and the random effect of farm. One farm did not record any treatment events, and thus was excluded from all producer-reported health event models $(\mathrm{n}=56$ calves; FIX $=27, \mathrm{INC}=29)$. For the technician-recorded health score data, which was available for all 5 farms, models were assessed to 
Table 1. Enrollment characteristics of a study investigating the effect of a fixed versus increasing milk allowance in the first weeks of life on health and performance of individually housed Holstein dairy heifers during the preweaning period during 2 seasons on 5 dairy farms in Minnesota

\begin{tabular}{lccc}
\hline Variable & FIX $^{1}$ & INC $^{2}$ & $P$-value \\
\hline Total enrollment $(\mathrm{n})$ & 641 & 623 & \\
Birth weight $(\mathrm{kg})$ & $38.2 \pm 0.2$ & $38.2 \pm 0.2$ & 0.92 \\
Serum total protein $(\mathrm{g} / \mathrm{dL})$ & $5.8 \pm 0.02$ & $5.8 \pm 0.03$ & 0.55 \\
\hline
\end{tabular}

${ }^{1}$ Fixed level allowance: calves allowed highest level of milk offered to calves on the dairy, from birth.

${ }^{2}$ Increasing allowance: calves were slowly increased their milk allowance over the first 7-14 d of life.

determine the odds of a health score of DIA, RESP, or SICK during the first $3 \mathrm{wk}$, accounting for repeated measures by week. Final significance for all models was determined at $P<0.05$.

\section{RESULTS}

\section{General Calf Enrollment and Calf Management}

One thousand two hundred and sixty-four calves were enrolled over the study period (FIX $\mathrm{n}=641$; INC $\mathrm{n}=$ 623 ) on 5 farms. Farms ranged in size from 810 to 5,500 milking cows. Farms 1, 2, 4, and 5 individually housed calves in hutches or in individual pens within naturally ventilated barns. On farm 3, which used pair housing, the pair of calves in each pen was allocated to FIX or INC. All calves were bedded with straw. Calves did not differ by enrollment characteristics between the 2 groups (Table 1). More calves were enrolled during the summer enrollment period $(\mathrm{n}=725)$ compared with the winter enrollment period $(\mathrm{n}=539)$ due to the fact that, because of a transfer in ownership, calves were not enrolled from farm 2 during the winter 2017 enrollment period. Peak feeding levels among the 5 farms varied from 6 to $8 \mathrm{~L} / \mathrm{d}$, with time to peak feeding level varying from 7 to $14 \mathrm{~d}$. All farms fed pasteurized waste or whole milk, with 3 farms feeding additional balancer in the milk (Land O' Lakes Pasteurized Milk Balancer, Land O'Lakes Animal Milk Products, Shoreview, MN; Famo Enhancer 25:10 and Famo Gold Milk 20:20, Famo
Feeds Inc., Freeport, MN). All farms began offering calf starter in the first days of life with the exception of farm 2, which offered starter beginning at $14 \mathrm{~d}$ of age. One farm fed a commercial product (Purina Ampli-Calf $22 \%$ Texturized Calf Starter, Land O' Lakes), whereas the remaining study farms offered custom mixed starters as described in Table 2. The total volume of extra milk provided to FIX calves compared with INC calves over the course of the 1- to 2-wk period ranged from 7.5 to $42 \mathrm{~L}$ depending on farm. The average FIX calf consumed an extra $14 \mathrm{~L}$ of milk as compared with INC calves, corresponding to an average INC intake of $5 \mathrm{~L} / \mathrm{d}$ during the slowly increasing period as compared with an average intake of $6.8 \mathrm{~L} / \mathrm{d}$ in FIX calves. The average daily ambient temperature was $26.6^{\circ} \mathrm{C}$ in the summer and $-1.6^{\circ} \mathrm{C}$ in the winter portion of the study period [Minnesota Department of Natural Resources (St. Paul) weather station data]. Table 3 provides values for calf dietary maintenance and growth for each diet and each season, as calculated by the Nutrient Requirements of Dairy Cattle (NRC, 2001).

\section{Calf Growth}

Weight information from electronic scales were available for 954 calves (FIX $\mathrm{n}=489$; INC $\mathrm{n}=465$ ). It should be noted that the digital scales failed at some of the weekly winter farm visits due to extreme cold, in which case weights were estimated with a weight tape

Table 2. The composition of calf starter fed on all study farms on an as-fed basis

\begin{tabular}{lcccccc}
\hline Variable & Farm $1^{1}$ & Farm $1^{2}$ & Farm $2^{2}$ & Farm $3^{3}$ & Farm $4^{4}$ \\
\hline Days offered & $2-28$ & 28 to wean & 14 to wean & 2 to wean & 4 to wean & 2 to wean \\
CP (\%) & 22 & 22.7 & 22.7 & 21.2 & 20.1 & 3.7 \\
Crude fat (\%) & 2.5 & 4.9 & 4.9 & 3.8 & 1.2 & 1.2 \\
Ca (\%) & 1.5 & 1.5 & 1.5 & 0.6 & 0.6 & 0.1 \\
P (\%) & 0.5 & 0.7 & 0.7 & 36,605 & 35,200 \\
Vitamin A (IU/kg) & 27,500 & 31,944 & 31,944 & & 27,500 \\
\hline
\end{tabular}

${ }^{1}$ Purina Ampli-Calf (Land O'Lakes, Inc., Shoreview, MN).

${ }^{2}$ Custom $22 \%$ CP starter (AgPartners Co-operative, Goodhue, MN).

${ }^{3}$ Custom 20\% CP starter (United Farmers Co-operative, Winthrop, MN).

${ }^{4}$ Custom $20 \%$ CP starter (AgPartners Co-operative).

${ }^{5}$ Custom $20 \%$ CP starter (Famo Feeds Inc., Freeport, MN). 
Table 3. Estimated average energy and protein available for growth for the average $\mathrm{FIX}^{1}(6.8 \mathrm{~L} / \mathrm{d})$ and $\mathrm{INC}^{2}$ $(5 \mathrm{~L} / \mathrm{d})$ milk intake per enrolled calf for both winter and summer seasons ${ }^{3}$

\begin{tabular}{lccccc}
\hline & \multicolumn{2}{c}{ Summer $\left(26.6^{\circ} \mathrm{C}\right)$} & & \multicolumn{2}{c}{ Winter $\left(-1.6^{\circ} \mathrm{C}\right)$} \\
\cline { 2 - 3 } \cline { 5 - 6 } Variable & \multirow{2}{*}{ FIX } & INC & & \multirow{2}{*}{ FIX } & \multirow{2}{*}{ INC } \\
\hline Total DMI $(\mathrm{kg} / \mathrm{d})$ & 0.85 & 0.63 & & 0.85 & 0.63 \\
DMI required for maintenance $(\mathrm{kg} / \mathrm{d})$ & 0.29 & 0.29 & & 0.44 & 0.44 \\
DMI available for growth $(\mathrm{kg} / \mathrm{d})$ & 0.56 & 0.34 & & 0.41 & 0.18 \\
Diet ME (Mcal/kg) & 5.37 & 5.37 & & 5.37 & 5.37 \\
ME required for maintenance (Mcal/d) & 1.54 & 1.54 & & 2.37 & 2.37 \\
ME available for growth (Mcal/d) & 3.02 & 1.82 & & 2.20 & 0.99 \\
Energy allowable ADG (kg/d) & 0.99 & 0.65 & & 0.76 & 0.39 \\
Protein allowable ADG (kg/d) & 0.74 & 0.52 & & 0.74 & 0.52 \\
\hline
\end{tabular}

${ }^{1}$ Fixed level allowance: calves allowed highest level of milk offered to calves on the dairy, from d 1.

${ }^{2}$ Increasing allowance: calves were slowly increased their milk allowance over the first 7-14 d of life.

${ }^{3}$ These calculations assume consumption of whole milk $(25.8 \% \mathrm{CP}$ and $30.8 \%$ crude fat $)$ and daily average ambient winter and summer temperatures during the time of the study taken from weather stations within a $16-\mathrm{km}$ radius from each study farm. All values were calculated using the NRC (2001) assuming a 38.2-kg calf (average birth weight in the present study) and no starter grain consumption.

(The Coburn Company Calf Weight Tape, Whitewater, WI). However, those calves weighed with a weight tape were removed from analysis of weight gains (FIX $\mathrm{n}=63 ;$ INC $\mathrm{n}=77$ ) due to questionable accuracy of that weight measurement method compared with the electronic scale-derived weights. Overall, calves in the FIX group gained an average (SE) of $1.35(0.59) \mathrm{kg}$ $(P=0.0004)$ more in the first 3 wk of life compared with INC calves after controlling for the effect of season, birth weight, time to peak milk, the interaction of treatment group $\times$ season and treatment group $\times$ time to peak milk, and the random effect of calf within farm (Table 4). The effect of treatment on weight at $3 \mathrm{wk}$ varied by duration to peak milk allowance $(7,10$, or 14 d) as no difference in weight was found at 3 wk between INC and FIX calves that were allowed extra milk for $7 \mathrm{~d}(P=0.98)$, whereas FIX calves allowed extra milk for $14 \mathrm{~d}$ weighed $1.7(0.8) \mathrm{kg}$ more than INC calves at wk 3 of life $(P<0.0003$; Table 5$)$. The effect of treatment on wk 3 weight was modified by season, with FIX calves weighing $2.3(0.7) \mathrm{kg}$ more than INC calves in the summer $(P<0.002)$, whereas FIX calves weighed $1.7(0.8) \mathrm{kg}$ more than INC calves in the winter $(P=$ 0.11 ; Table 6 ).

The overall effect of treatment on ADG $(\mathrm{kg} / \mathrm{d})$ at 3 wk was $0.11(0.03) \mathrm{kg} / \mathrm{d}$ higher in FIX calves compared

Table 4. Results of a linear mixed model investigating the effect a fixed versus increasing milk allowance in the first weeks of life on BW (kg) at $3 \mathrm{wk}$ of age

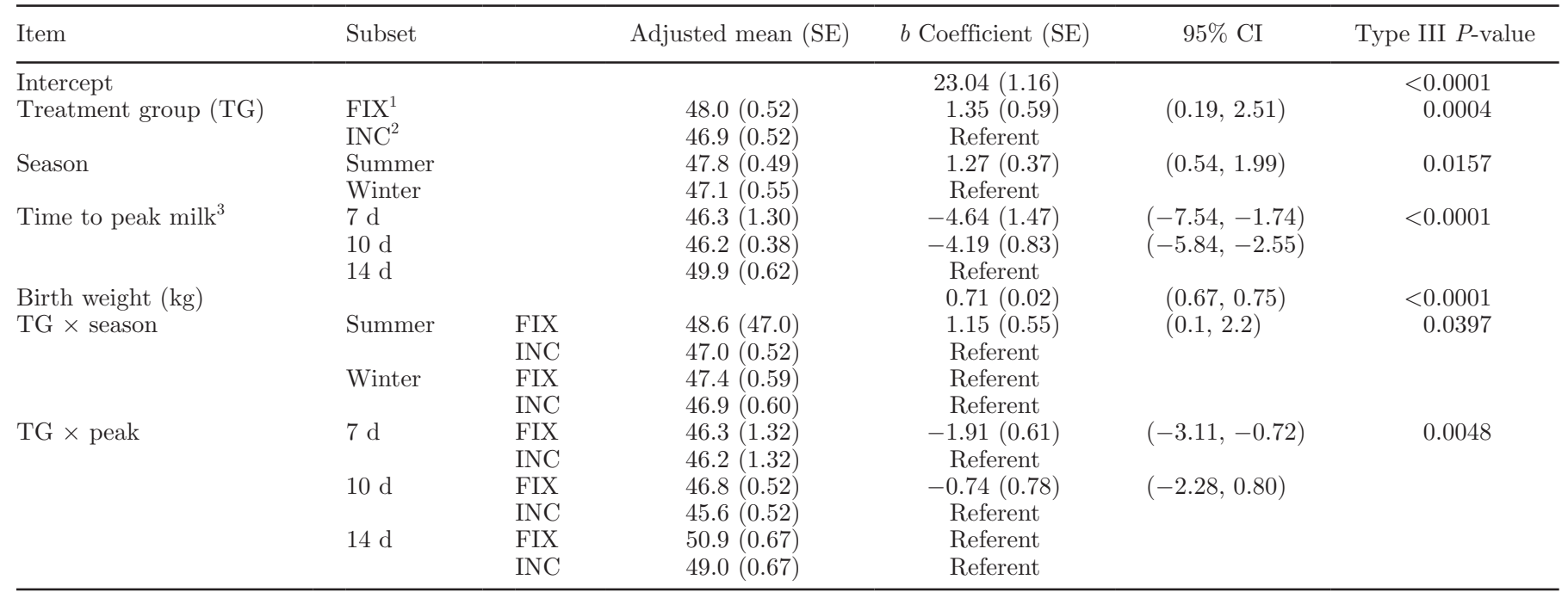

${ }^{1}$ Fixed level allowance: calves allowed the peak daily milk allowance (L/d) from d 1 after birth.

${ }^{2}$ Increasing allowance: calves were slowly increased their milk allowance over the first 7-14 d of life (duration varied by farm).

${ }^{3}$ The time that it takes the farm to reach peak milk feeding $(7 \mathrm{~d}$ : farm 2 and farm $5 ; 10 \mathrm{~d}$ : farm 1 and farm $4 ; 14 \mathrm{~d}$ : farm 3). 
Table 5. Results of a linear mixed model stratified by duration of the time to peak milk allowance investigating the effects of a fixed versus increasing milk allowance in the first weeks of life on $\mathrm{BW}(\mathrm{kg})$ at 3 wk and $\mathrm{ADG}(\mathrm{kg} / \mathrm{d})$ to 3 wk in preweaning dairy calves

\begin{tabular}{|c|c|c|c|c|c|}
\hline Item & Group & $\mathrm{n}$ & $b$ Coefficient (SE) & Adjusted mean (SE) & Type III $P$-value \\
\hline \multicolumn{6}{|c|}{ Weight $(\mathrm{kg})$ at $3 \mathrm{wk}^{1}$} \\
\hline $7 \mathrm{~d}($ farm 2,5$)$ & FIX $^{2}$ & 338 & $-0.79(0.71)$ & $45.1(1.69)$ & 0.98 \\
\hline \multirow[t]{2}{*}{$10 \mathrm{~d}($ farm 1,4$)$} & FIX & 52 & \multirow[t]{2}{*}{$1.58(0.91)$} & $47.8(0.44)$ & \multirow[t]{2}{*}{0.047} \\
\hline & INC & 50 & & $46.6(0.43)$ & \\
\hline \multirow[t]{2}{*}{$14 \mathrm{~d}($ farm 3$)$} & FIX & 99 & \multirow[t]{2}{*}{$1.74(0.82)$} & $50.5(0.65)$ & \multirow[t]{2}{*}{0.0003} \\
\hline & \multicolumn{3}{|c|}{ ADG $(\mathrm{kg} / \mathrm{d})$ birth to $3 \mathrm{wk}^{4}$} & & \\
\hline $7 \mathrm{~d}($ farm 2,5$)$ & INC & 300 & $0.03(0.01)$ & $0.34(0.09)$ & 0.0210 \\
\hline \multirow[t]{2}{*}{$10 \mathrm{~d}($ farm 1,4$)$} & FIX & 51 & \multirow[t]{2}{*}{$0.07(0.03)$} & $0.44(0.02)$ & \multirow[t]{2}{*}{0.042} \\
\hline & INC & 49 & & $0.37(0.02)$ & \\
\hline \multirow[t]{2}{*}{$14 \mathrm{~d}($ farm 3$)$} & FIX & 99 & \multirow[t]{2}{*}{$0.11(0.03)$} & $0.68(0.03)$ & \multirow[t]{2}{*}{0.0002} \\
\hline & INC & 99 & & $0.57(0.03)$ & \\
\hline
\end{tabular}

${ }^{1}$ This model controlled for the effect of birth weight, season, season $\times$ treatment group, and the random effect of calf within farm.

${ }^{2}$ Fixed level allowance: calves allowed the peak daily milk allowance (L/d) from d 1 after birth.

${ }^{3}$ Increasing allowance: calves were slowly increased their milk allowance over the first $7-14 \mathrm{~d}$ of life (duration varied by farm).

${ }^{4}$ This model controlled for the effect of birth weight, season, and the random effect of calf within farm.

with INC calves after controlling for the effect of season, birth weight, time to peak milk, the interaction of treatment group and time to peak milk, and the random effect of calf within farm (Table 7). The magnitude of this positive effect also differed by time to peak milk allowance, in that FIX calves allowed extra milk for 7 $\mathrm{d}$ had an advantage of $0.03(0.01) \mathrm{kg} / \mathrm{d}(P=0.021)$ compared with INC calves, whereas FIX calves allowed $14 \mathrm{~d}$ of extra milk had an advantage of $0.11(0.03) \mathrm{kg} / \mathrm{d}$ to 3 wk of age compared with INC calves $(P<0.0001$; Table 5). The magnitude of this effect also varied by season, with FIX calves having an advantage of 0.06 $(0.01) \mathrm{kg} / \mathrm{d}(P<0.0001)$ compared with INC calves during the summer portion of the study, but with FIX calves only having an advantage of $0.04(0.03) \mathrm{kg} / \mathrm{d}$ $(P=0.07)$ over INC calves in the winter (Table 6$)$.
We recorded 1,234 hip heights for wk 1 analysis (FIX $\mathrm{n}=631 ; \mathrm{RU} \mathrm{n}=603)$ and found no difference in hip height between treatment groups $(P=0.96)$ at wk 1 . However, at wk 3 of life, FIX calves were $0.3(0.15) \mathrm{cm}$ taller $(P=0.0482)$ than INC calves after controlling for the effect of season, birth weight, and the random effect of calf within farm (Table 8). This difference did not persist to wk 7 of life $($ FIX $=89.4 \mathrm{~cm}, \mathrm{INC}=89.2$ $\mathrm{cm} ; P=0.23)$.

\section{Calf Health}

Overall, 42\% (536/1264) of all enrolled calves had a producer-reported first treatment event between birth and weaning at an average (SD) of 11.3 (10.2) days of age. The majority of first treatment events were for

Table 6. Results of a linear mixed model stratified by season investigating the effects of a fixed versus increasing milk allowance in the first weeks of life on $\mathrm{BW}(\mathrm{kg})$ at $3 \mathrm{wk}$ and $\mathrm{ADG}(\mathrm{kg} / \mathrm{d})$ to $3 \mathrm{wk}$ in preweaning dairy calves

\begin{tabular}{|c|c|c|c|c|c|}
\hline Item & Group & $\mathrm{n}$ & $b$ Coefficient (SE) & Adjusted mean (SE) & Type III $P$-value \\
\hline \multicolumn{6}{|c|}{ Weight $(\mathrm{kg})$ at $3 \mathrm{wk}^{1}$} \\
\hline \multirow[t]{2}{*}{ Summer } & $\mathrm{FIX}^{2}$ & 330 & \multirow[t]{2}{*}{$2.30(0.65)$} & $47.7(0.56)$ & \multirow[t]{2}{*}{0.0002} \\
\hline & $\mathrm{INC}^{3}$ & 336 & & $46.4(0.57)$ & \\
\hline Winter & INC & 129 & $1.70(0.80)$ & $48.4(2.4)$ & 0.1113 \\
\hline \multicolumn{6}{|c|}{ ADG $(\mathrm{kg} / \mathrm{d})$ at $3 \mathrm{wk}^{4}$} \\
\hline Summer & FIX & 329 & $0.06(0.01)$ & $0.50(0.03)$ & $<0.0001$ \\
\hline Winter & INC & 113 & $0.04(0.03)$ & $0.52(0.12)$ & 0.07 \\
\hline
\end{tabular}

${ }^{1}$ This model controlled for the effect of birth weight, time to peak milk allowance, the interaction between time to peak milk allowance and treatment group, and the random effect of calf within farm.

${ }^{2}$ Fixed level allowance: calves allowed the peak daily milk allowance (L/d) from d 1 after birth.

${ }^{3}$ Increasing allowance: calves were slowly increased their milk allowance over the first $7-14 \mathrm{~d}$ of life (duration varied by farm).

${ }^{4}$ This model controlled for the effect of birth weight, time to peak milk allowance, and the random effect of calf within farm. 
Table 7. Results of a linear mixed model investigating the effect of a fixed versus increasing milk allowance in the first weeks of life on ADG $(\mathrm{kg} / \mathrm{d})$ to $3 \mathrm{wk}$ in preweaning dairy calves

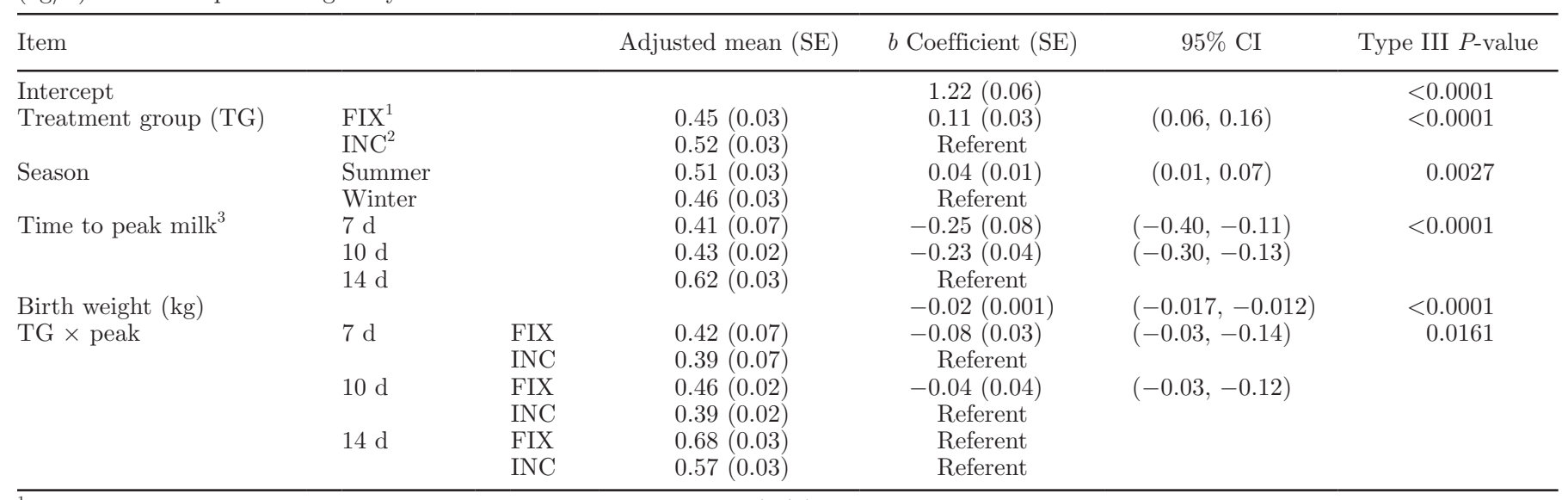

${ }^{1}$ Fixed level allowance: calves allowed the peak daily milk allowance (L/d) from d 1 after birth.

${ }^{2}$ Increasing allowance: calves were slowly increased their milk allowance over the first 7-14 d of life (duration varied by farm).

${ }^{3}$ The time that it takes the farm to reach peak milk feeding $(7 \mathrm{~d}$ : farm 2 and farm $5 ; 10 \mathrm{~d}$ : farm 1 and farm $4 ; 14 \mathrm{~d}$ : farm 3).

diarrhea $(76 \%, 408 / 536)$ and respiratory disease $(16 \%$, $86 / 536)$. A total of $1.5 \%(19 / 1264)$ of all enrolled calves died during the observation period, with no effect of treatment on mortality $(P=0.87)$. We found no effect of treatment on the odds of a producer reported first treatment event [FIX $=46.7 \%, \mathrm{INC}=41.9 \%$; odds ratio $=1.2(95 \%$ CI: $0.95,1.51) ; P=0.13]$, but the odds of treatment was higher for calves born in the winter compared with the summer $[\mathrm{WIN}=50.1 \%$, $\mathrm{SUM}=40.0 \%$; odds ratio $=1.9(95 \%$ CI: $1.5,2.4) ; P$ $<0.0001$; Table 9). Overall, we found no difference in risk for producer-reported diagnosis for scours between FIX and RU calves [FIX $=36.1 \%$, INC $=32.2 \%$; odds ratio $=1.2(95 \% \mathrm{CI}: 0.91,1.51) P=0.21]$, although a trend for the interaction between farm and treatment existed $(P=0.16)$, which was subsequently explored by stratifying the analysis by farm. After controlling for season, farm 5 had a higher odds of a producerreported clinical diagnosis of scours in the FIX group $[\mathrm{FIX}=37.2 \%, \mathrm{INC}=29.4 \%$, odds ratio $=1.4(95 \%$ CI: $1.03,1.85) P=0.03]$, but this was not true for the other 3 farms with recorded treatment events [FIX = $33.3 \%, \mathrm{INC}=38.5 \%$; odds ratio 0.79 (95\% CI: 0.51 , 1.23) $P=0.31]$.

Technician health scoring was completed for all enrolled calves for the first 3 wk of life, consisting of 3,692 health scores (FIX $\mathrm{n}=1,873$; INC $\mathrm{n}=1,819$ ). We found no effect of treatment on the odds of DIA at any time during the first $3 \mathrm{wk}$ of life (Table 10). Very few health scores indicated RESP, so RESP and DIA were combined to describe a calf as SICK. We observed no effect of treatment on the odds of a SICK health score in any of the first $3 \mathrm{wk}$ of life (Table 10). The odds of a calf having a SICK or DIA health score was greater during the winter (as compared with summer) in wk 1 of life, not different at wk 2 , and lower at wk 3 (results not shown).

\section{DISCUSSION}

Although previous observational studies have suggested possible benefits of offering more milk in the

Table 8. Results of a linear mixed model investigating the effect of a fixed versus increasing milk allowance in the first weeks of life on hip height $(\mathrm{cm})$ at 3 wh of age in preweaning dairy calves

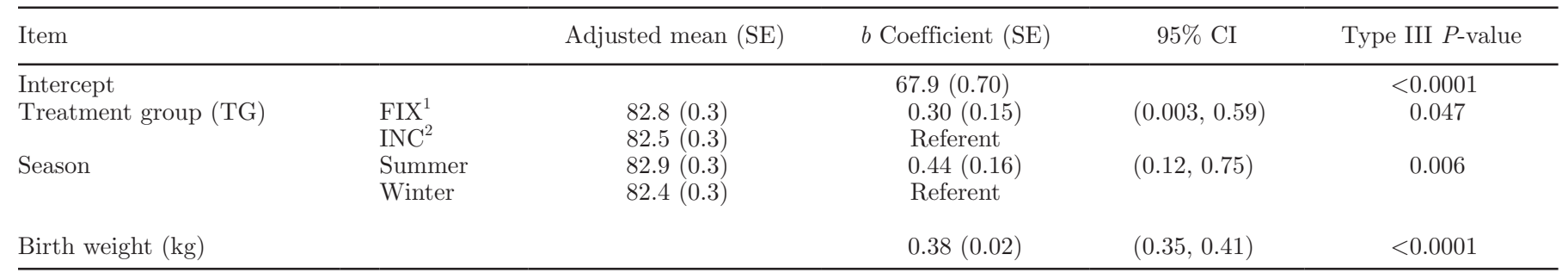

${ }^{1}$ Fixed level allowance: calves allowed the peak daily milk allowance (L/d) from d 1 after birth.

${ }^{2}$ Increasing allowance: calves were slowly increased their milk allowance over the first $7-14 \mathrm{~d}$ of life (duration varied by farm). 
Table 9. Results of a mixed multivariable logistic regression model describing the effect of a fixed versus increasing milk allowance in the first weeks of life on the odds of producer-reported first treatment event in preweaning dairy calves ${ }^{1}$

\begin{tabular}{llccc}
\hline \multirow{2}{*}{ Odds of a first treatment event } & Group & $\begin{array}{c}\text { Crude proportion affected } \\
{[\% \text { (no./no.) }}\end{array}$ & $b$ Coefficient (SE) & $\begin{array}{c}\text { Odds ratio } \\
(95 \% \text { CI })\end{array}$ \\
\hline Treatment $^{2}$ & FIX & $46.7(287 / 614)$ & $0.18(0.12)$ & $1.2(0.95,1.51)$ \\
& INC & $41.9(249 / 594)$ & Referent & 0.13 \\
Season $^{3}$ & WIN & $50.1(261 / 521)$ & $0.64(0.12)$ & $1.88(1.49,2.40)$ \\
& SUM & $40.0(275 / 687)$ & Referent & \\
\hline
\end{tabular}

${ }^{1}$ This model controlled for the effect of season and the random effect of farm.

${ }^{2}$ Treatment $($ FIX $=$ fixed allowance from d 1 of life; INC = slowly increasing milk allowance over the first 7-14 d of life).

${ }^{3}$ Season $($ WIN $=$ Dec.-Feb. 2017; SUM = Jun.-Aug. 2016).

days after birth compared with traditional programs that slowly increase the daily milk allowance over the first 1 to $3 \mathrm{wk}$ of life, to our knowledge this is the first randomized clinical trial investigating this question. We found that calves offered a fixed level of milk from $\mathrm{d} 1$ of life were $1.35 \mathrm{~kg}$ heavier and $0.3 \mathrm{~cm}$ taller at $3 \mathrm{wk}$ of age than calves reared in the traditional fashion. The average FIX calf was offered an extra $14 \mathrm{~L}$ of whole milk during the study; to state this another way, the average INC calf received a total of $5 \mathrm{~L} / \mathrm{d}$ during the first 1 to 2 wk of life compared with $6.8 \mathrm{~L} / \mathrm{d}$ in the FIX group. We were not able to collect representative milk samples for milk component analysis, but we can assume that the average waste milk offered had CP and crude fat contents of 25.4 and $30.8 \%$, respectively (NRC, 2001). Calves in the FIX group consumed 0.22 $\mathrm{kg}$ more DM than calves in the INC group, corresponding to more energy available for growth, especially in the winter months. The difference in NRC-predicted ADG between FIX and INC calves was 0.22 and 0.35 $\mathrm{kg} / \mathrm{d}$ in the summer and winter months, respectively. This is a much bigger difference than was predicted by our models $(0.06 \mathrm{~kg} / \mathrm{d}$ in summer; $0.04 \mathrm{~kg} / \mathrm{d}$ in winter). The reasons for this disparity in model predictions are multifactorial and include the rigidity of the NRC model, small differences in milk intake and components by farm and calf, and the effect of other factors such as ambient temperature fluctuations and health challenges.

It has been well documented that low ambient temperatures dramatically change the energy requirements of the preweaning calf (Drackley, 2008). This analysis highlights the effect of increased nutrients available for calf growth in addition to the importance of nutrient availability to the calf during the winter months. In addition to ADG results, in the present study we observed that season changed the magnitude of the effect of offering a fixed milk allowance from birth on calf BW at 3 wk. Though the difference in BW between FIX and INC was not statistically significant during the winter, calves in the FIX group were $1.7-\mathrm{kg}$ heavier than INC calves, which represents a biologically significant difference.

We also noted an advantage of the intervention for FIX calves raised on farms that increased milk allowance over a longer time period (e.g., 14 vs $7 \mathrm{~d}$ ), presumably due to a larger disparity in total volume of milk offered and, therefore, a larger disparity in total nutrient intake between the 2 treatment groups within those herds that used a longer time period to bring calves to peak milk feeding levels. Calves on all farms except farm 2 offered at least a $20 \%$ CP starter grain in the first days of life (farm 2 offered $20 \%$ CP starter beginning at $14 \mathrm{~d}$ of age); however, we do not expect a large effect of starter on growth in the first $3 \mathrm{wk}$ of life, as young calves do not consume large amounts of starter (Steele et al., 2017). Though we only had ADG data available to $3 \mathrm{wk}$, and not to weaning, the model-adjusted ADG reported in our study are similar to those that have been reported in studies feeding both whole milk (Godden et al., 2005) and milk replacer with similar components to whole milk (Brown et al.,

Table 10. Results of linear mixed regression analysis describing the effect of a fixed versus increasing milk allowance in the first weeks of life on technician-reported health scores (DIA $=$ fecal score $\geq 2$; SICK $=$ fecal score $\geq 2$ or respiratory score $\geq 2$ ) at any time in the first 3 wk of life ${ }^{1}$

\begin{tabular}{|c|c|c|c|c|c|}
\hline Outcome & Treatment group ${ }^{2}$ & $\begin{array}{c}\text { Crude proportion affected } \\
[\% \text { (no. } / \text { no. })]\end{array}$ & $b$ Coefficient (SE) & Odds ratio $(95 \% \mathrm{CI})$ & Type III $P$-value \\
\hline DIA & FIX & $22(398 / 1806)$ & $-0.08(0.08)$ & $0.92(0.78,1.08)$ & 0.29 \\
\hline
\end{tabular}

${ }^{1}$ The final models control for the random effect of farm and repeated measurements by week.

${ }^{2}$ Treatment group (FIX $=$ fixed level milk allowance from d 1 of life; INC $=$ increasing milk allowance over the first $7-14 \mathrm{~d}$ of life). 
2005; Foote et al., 2005; Rosenberger et al., 2017). We found no hip height advantage for FIX calves at $7 \mathrm{wk}$, suggesting that the effects of this program may be short term. A limitation of our work is that we did not collect wk-7 weights, so we cannot speculate as to the effect of treatment on BW later during the preweaning period of the calf.

Contrary to the long-held industry dogma that feeding more milk early in life will result in nutritional scours, FIX calves in the present study did not have higher odds of overall treatment by farm workers and had similar technician-reported fecal and health scores compared with INC calves. The majority of studies that reported fecal scores reported that calves fed a higher plane of nutrition (intensified feeding programs) had higher fecal scores than calves fed conventional diets due to an increased volume of liquid consumed (Diaz et al., 2001; Nonnecke et al., 2003; Liang et al., 2016). However, producers should not confuse the softer stools normally resulting from consuming higher volumes of milk as evidence for a sick (scouring) calf. It is true that FIX calves on farm 5 had a higher odds of a producerreported clinical scour treatment than INC calves (FIX $=37.2 \%, \mathrm{INC}=29.4 \%$ ), though this was not true for the other 4 enrolled farms. However, this finding is inconsistent with the fact that technician-reported fecal scores and health scores were not different between treatment groups on farm 5 . It is also inconsistent with the fact we found no difference in growth between FIX and INC calves on farm 5 during the first 3 wk of life (model-adjusted mean 3-wk weight: FIX $=49.6$; INC $=49.5 ; P=0.92$ ). If FIX calves were truly at increased risk of clinical scours on farm 5 , then growth rates in this group would be expected to be reduced compared with to INC calves. Davis Rincker et al. (2011) and Brown et al. (2005) reported that calves fed an intensified milk feeding level had higher fecal scores than conventionally fed calves, with no difference between groups in mortality (Brown et al., 2005) or days treated (Davis Rincker et al., 2011). Conversely, Raeth-Knight et al. (2009) reported that calves fed an intensified diet had higher fecal scores and numerically more cost associated with treatment for scours compared with calves fed conventionally. However, those authors did not describe if or how they blinded study technicians, calf feeders, or farm personnel in their studies. One possible explanation for the discrepancies observed on farm 5 for our study may lay in the fact that we could not blind calf workers to treatment groups, as we had to visually mark calf pens and hutches so that calves could be fed the appropriate level of milk by the feeding crew. It is possible that workers on farm 5 may have been watching FIX calves more closely, resulting in a treatment bias. Given that calves in the FIX group were offered a greater volume of liquid diet, we expected more calves with softer feces in the FIX group in the first 2 wk of life. However, the technician-reported fecal score findings did not support this hypothesis.

Whereas our intervention resulted in improved growth and equal health for FIX calves, producers will want to know if offering a fixed milk allowance from birth is economically justified. Many factors influence costs of this type of program, including the type of milk or milk replacer offered, amount and cost of milk refusal early in life, starter consumption, extra labor to deliver milk, and extra milk feeding equipment. The fact that we did not measure all of these factors paired with only measuring ADG to 3 wk makes it very difficult to calculate a valid cost for this type of program. We plan to follow study calves through their first and second lactation to investigate possible long-term health and performance benefits including milk yield and longevity in the herd.

Strengths of our study include the fact that it was a large, adequately powered, randomized clinical trial conducted on 5 different commercial Midwest dairy farms. One limitation to study design is the fact that we could not blind farm staff to treatment group. This could have potentially introduced a treatment bias when considering producer-reported health effects. However, the inclusion of technician-reported health scores improved the robustness of our evaluation of the effect of treatment on health outcomes. Though not a perfect measure, as we are comparing weekly health scores to daily observations, this way we can compare the 2 measures to help determine if a treatment bias by farm personnel is occurring. Furthermore, the use of objective measures, such as electronically recorded calf weights at birth and $3 \mathrm{wk}$, avoided any possibility of bias relating to growth outcomes. Because all 5 study herds fed pasteurized whole milk, we should be cautious generalizing results to herds that feed milk replacer.

\section{CONCLUSIONS}

Under the conditions of this study, a fixed level allowance during the first days and weeks of life resulted in a growth advantage at 3 wk of age and no detriment to calf health compared with calves fed milk in the traditional manner. Additionally, the growth advantage was greatest for farms that had the longest duration of time to peak milk allowance, and therefore for the calves fed the greatest difference in volume of milk. Our results show that offering a fixed milk level from $\mathrm{d} 1$ of life results in better growth early in life as compared with calves slowly increased to a fixed level over the first 7 to $14 \mathrm{~d}$ of life, and that this calf-feeding strategy can be applied at the farm level with no detriment to animal health. 


\section{ACKNOWLEDGMENTS}

The authors thank Land O'Lakes Animal Milk Products (Shoreview, MN) and especially Tom Earleywine for their in-kind support of this project. A special thanks also to our student workers who collected all of the data including Isaac Secor, Jordan Sanford, Mary Liebenstein, Elizabeth Binger, Carol Resende, and Tuyet Nguyen. Also to our producers, without whom none of this would have been possible.

\section{REFERENCES}

Ballou, M. A., D. L. Hanson, C .J. Cobb, B. S. Obeidat, M. D. Sellers, A. R. Pepper-Yowell, J. A. Carroll, T. J. Earleywine, and S. D. Lawhon. 2015. Plane of nutrition influences the performance, innate leukocyte responses, and resistance to an oral Salmonella enterica serotype Typhimurium challenge in Jersey calves. J. Dairy Sci. 98:1972-1982.

Bar-Peled, U., B. Robinzon, E. Maltz, H. Tagari, Y. Folman, I. Bruckental, H. Voet, H. Gacitua, and A. R. Lehrer. 1997. Increased weight gain and effects on production parameters of Holstein heifer calves that were allowed to suckle from birth to six weeks of age. J. Dairy Sci. 80:2523-2528.

Brown, E. G., M. J. VandeHarr, K. M. Daniels, J. S. Liesman, L. T. Chapin, D. H. Keisler, and M. S. Weber Nielsen. 2005. Effect of increasing energy and protein intake on body growth and carcass composition of heifer calves. J. Dairy Sci. 88:585-594.

Davis Rincker, L. E., M. J. VandeHaar, C. A. Wolf, J. S. Liesman, L. T. Chapin, and M. S. Weber Nielsen. 2011. Effects of intensified feeding of heifer calves on growth, pubertal age, calving age, milk yield, and economics. J. Dairy Sci. 94:3554-3567.

de Passillé, A. M., M. Rabeyrin, and J. Rushen. 2014. Associations between milk intake and activity in the first days of a calf's life and later growth and health. Appl. Anim. Behav. Sci. 175:2-7.

DeNise, S. K., J. D. Robison, G. H. Stott, and D. V. Armstrong. 1989. Effects of passive immunity of subsequent production in dairy heifers. J. Dairy Sci. 72:552-554.

Diaz, M. C., M. E. Van Amburgh, J. M. Smith, J. M. Kelsey, and E. L. Hutten. 2001. Composition of growth of Holstein calves fed milk replacer from birth to 105-kilogram body weight. J. Dairy Sci. 84:830-842.

Drackley, J. K. 2008. Calf nutrition from birth to breeding. Vet. Clin. North Am. Food Anim. Pract. 24:55-86.

Faber, S. N., N. E. Faber, T. C. McCauley, and R. L. Ax. 2005. Effects of colostrum ingestion on lactational performance. Prof. Anim. Sci. 21:420-425.

Foldager, J., and C. C. Krohn. 1994. Heifer calves reared on very high or normal levels of whole milk from birth to $6-8$ weeks of age and their subsequent milk production. Proc. Soc. Nutr. Physiol. 3:301.

Foote, M. R., B. J. Nonnecke, M. A. Fowler, B. L. Miller, D. C. Beitz, and W. R. Walters. 2005. Effects of age and nutrition on expression of CD25, CD44, and L-selectin (CD62L) on T-cells from neonatal calves. J. Dairy Sci. 88:2718-2729.

Godden, S. M., J. P. Fetrow, J. M. Feirtag, L. R. Green, and S. J. Wells. 2005. Economic analysis of feeding pasteurized nonsalable milk versus conventional milk replacer to dairy calves. J. Am. Vet. Med. Assoc. 226:1547-1554.

Jasper, J., and D. M. Weary. 2002. Effects of ad libitum milk intake on dairy calves. J. Dairy Sci. 85:3054-3058.

Jorgensen, M. W., A. Adams-Progar, A. M. de Passille, J. Rushen, S. M. Godden, H. Chester-Jones, and M. I. Endres. 2017. Factors associated with dairy calf health in automated feeding systems in the Upper Midwest United States. J. Dairy Sci. 100:5675-5686.

Liang, Y., J. A. Carroll, and M. A. Ballou. 2016. The digestive system of 1-week old Jersey calves is well suited to digest, absorb, and incorporate protein and energy into tissue growth even when calves are fed a high plan of milk replacer. J. Dairy Sci. 99:1929-1937.

McGuirk, S. 2008. Disease management of dairy calves and heifer. Vet. Clin. North Am. Food Anim. Pract. 24:139-153.

NRC. 2001. Computer model program for predicting nutrient requirements. Pages 214-233 in Nutrient Requirements of Dairy Cattle. 7th ed. Natl. Acad. Press, Washington, DC.

Nonnecke, B. J., M. R. Foote, J. M. Smith, B. A. Pesch, and M. E. Van Amburgh. 2003. Composition and functional capacity of blood mononuclear leukocyte populations from neonatal calves on standard and intensified milk replacer diets. J. Dairy Sci. 86:35923604.

Ollivett, T. L., D. V. Nydam, T. C. Linden, D. D. Bowman, and M. E. Van Amburgh. 2012. Effect of nutritional plan on health and performance in dairy calves after experimental infection with Cryptosporidium parvum. J. Am. Vet. Med. Assoc. 241:1514-1520.

Quigley, J. D., T. A. Wolfe, and T. H. Elsasser. 2006. Effects of additional milk replacer feeding on calf health, growth and selected blood metabolites in calves. J. Dairy Sci. 89:207-216.

Raeth-Knight, M., H. Chester-Jones, S. Hayes, J. Linn, R. Larson, D. Ziegler, B. Ziegler, and N. Broadwater. 2009. Impact of conventional or intensive milk replacer programs on Holstein heifer performance through six months of age and during first lactation. J. Dairy Sci. 92:799-809.

Rosenberger, K., J. H. C. Costa, H. W. Neave, M. A. G. von Keyserlingk, and D. M. Weary. 2017. The effect of milk allowance on behavior and weight gains in dairy calves. J. Dairy Sci. 100:504-512.

Soberon, F., E. Raffrenato, R. W. Everett, and M. E. Van Amburgh. 2012. Preweaning milk replacer intake and effects on long-term productivity of dairy calves. J. Dairy Sci. 95:783-793.

Soberon, F., and M. E. Van Amburgh. 2013. Lactation biology symposium: The effect of nutrient intake from milk or milk replacer of pre-weaned dairy calves on lactation milk yield as adults: a metaanalysis of current data. J. Anim. Sci. 91:706-712.

Steele, M. A., J. H. Doelman, L. N. Leal, F. Soberon, M. Carson, and J. A. Metcalf. 2017. Abrupt weaning reduces postweaning growth and is associated with alterations in gastrointestinal markers of development in dairy calves fed an elevated plane of nutrition during the preweaning period. J. Dairy Sci. 100:5390-5399.

USDA. 2010. Dairy 2007. Heifer calf health and management practices on U.S. Dairy Operations. Accessed Apr. 11, 2017. https://www .aphis.usda.gov/animal_health/nahms/dairy/downloads/dairy07/ Dairy07_ir_CalfHealth.pdf.

USDA. 2016. Dairy 2014. Dairy cattle management practices in the United States. Accessed Apr. 14, 2017. https://www.aphis.usda .gov/animal_health/nahms/dairy/downloads/dairy14/Dairy14 _dr_PartI.pdf 